\title{
Parents' Emotional and Social Experiences of Caring a Child with Cleft Lip and/or Palate
}

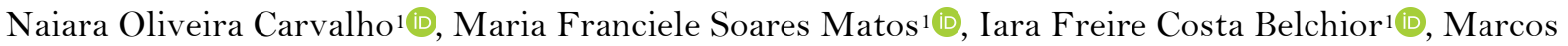

Bruno Araújo ${ }^{1}$, Cristiane Tomaz Rocha ${ }^{1}\left[\right.$, Beatriz Gonçalves Neves ${ }^{1}[$

${ }^{1}$ School of Dentistry, Federal University of Ceará, Sobral, CE, Brazil.

Correspondence: Beatriz Gonçalves Neves, Universidade Federal do Ceará, Campus Sobral, Rua Conselheiro José Júlio, S/N, Centro, Sobral, CE, Brazil.62010-820.E-mail: beatrizneves@ufc.br

Academic Editor: Ana Maria Gondim Valença

Received: 15 July 2020 / Review: 23 September 2020 / Accepted: 05 November 2020

How to cite: Carvalho NO, Matos MFS, Belchior IFC, Araújo MB, Rocha CT, Neves BG. Parents' emotional and social experiences of caring a child with cleft lip and/or palate. Pesqui Bras Odontopediatria Clín Integr. 2021; $21: e 0168$. https://doi.org/10.1590/pboci.2021.058

\footnotetext{
ABSTRACT

Objective: To evaluate the emotional and social experiences of parents or caregivers of children with cleft lip and/or palate (CL/P) in a city in the Northeastern of Brazil. Material and Methods: A quantitative and cross-sectional study was conducted among parents or caregivers of children with CL/P by interviews based on a questionnaire. Interviews were conducted during the First Smile Project in Sobral, Ceará, Brazil. All participants $(n=41)$ agreed to participate in the interview and signed an informed consent. The data was analyzed in SPSS software version 22.0. Results: The majority of participants were female (87.2\%), with a mean age of 37 years, with a low level of education and low family income. The great majority (90.2\%) of the parents were not prenatally diagnosed to have CL/P babies. Of those interviewed, $56.1 \%$ mentioned that the first diagnosis of cleft lip and palate was not presented by the professionals in a clarifying way to the family. Fear (36.6\%) and sadness (19.5\%) were the main feelings experienced when the child was diagnosed with fissure. Feeding (48.8\%) was pointed out as the main concern in caring for a child with CL/P. Conclusion: The parents and caregivers interviewed faced important emotional and social problems that must be addressed by the professional team that assists the child with CL/P.

Keywords: Clef Palate; Cleft Lip; Emotions; Parents; Caregivers.
} 


\section{Introduction}

The cleft lip and/or palate (CL/P) is the most common congenital defect that occurs in the population. This defect has a prevalence ranging from 1:500 to 1:2,500 live births [1], and the incidence in cases that are not associated with syndromes is around 0.8 per 1,000 births [2].

Its etiology is multifactorial, consisting of a combination of genetic and environmental factors, including family history of CL/P, parental consanguinity, maternal alcohol consumption, infections, smoking, hypertension, low supplementation of vitamins and minerals and consumption of analgesics, antibiotics and antihypertensives during pregnancy [2,3].

Children with CL/P might experience long-term treatment from birth to young adulthood to treat consequences of the condition relating to both function and appearance [4] because CL/P outcomes occur in the surgical, speech, hearing, dental, psychosocial, and cognitive aspects [5]. Early dental care is particularly important for children with CL/P because oral health plays a significant role in cleft-related outcomes. Good oral health, ideally resulting from regular home oral hygiene and professional dental care, influences a child's ability to obtain timely and adequate orthodontic treatment, which is an essential component of the reconstructive process and required precursor to surgery for children with CL/P [5].

$\mathrm{CL} / \mathrm{P}$ affects not just the child born with the condition, but also the child's parents. The timing of a child's diagnosis affects how parents cope and adapt. Prenatal diagnosis enables anticipatory guidance of the parents by professionals, which might improve the quality of the treatment received by the child and promote a better quality of life of the patient and family [6].

The literature reports various emotional reactions experienced by parents at the birth of a child with $\mathrm{CL} / \mathrm{P}$, such as shock, sadness, fear, grief, guilt, worry and anger, which may impact the families' lives [7]. Parents may wish to share their feelings and expectations and get emotional support from experienced professionals at the moment of the diagnosis, which may help them cope with these feelings properly and reorganize to meet the needs of their affected child [8].

Several studies have investigated the social and emotional difficulties among parents caring for children with clefts, such as anxiety, depression and poor psychological 'adjustment' [4,9-11]. However, there is still a lack of studies investigating these experiences faced by parents and/or caregivers of children with $\mathrm{CL} / \mathrm{P}$ in Brazil. Thus, considering that a long-term treatment pathway is usually experienced with a psychological impact on parents [12], the present study aimed to evaluate the emotional and social experiences of parents or caregivers of children with CL/P in a city in the Northeastern of Brazil.

\section{Material and Methods}

Study Design

A quantitative, descriptive and cross-sectional study was conducted among parents or caregivers of children with $\mathrm{CL} / \mathrm{P}$ by interviews based on a questionnaire.

\section{Sample Selection}

A convenience sampling was used for this study. Parents or caregivers that accompanied patients for oral clefts corrective surgery at the "Santa Casa de Misericórdia" Hospital in Sobral, Ceará, during a multiprofessional treatment campaign called "First Smile Project" were invited to participate in this study. The inclusion criteria were parents or caregivers who had at least 20 minutes to be interviewed. 
This hospital is a reference center in the care of patients with malformations of CL/P of the Northern region of the state of Ceará, Brazil. The city of Sobral is located in the state of Ceará, $235 \mathrm{~km}$ from the state capital, Fortaleza. It has an estimated population of 208,935 inhabitants and is considered the fifth most populous municipality in the state [13].

\section{Pilot Study}

A pilot study was carried out to assess the questionnaire proposed for the interview in order to verify if participants understood the questions asked. The questionnaire was designed by the authors and based on previous studies $[3,10]$. The parents or caregivers interviewed $(n=12)$ on the pretest were not included in the final sample. In addition, this phase was also used as training for interviewers, who consisted of dental undergraduate students that were participants of a project from the Dental School of the Federal University of Ceará directed to patients with oral clefts.

\section{Interview}

All volunteers were interviewed during the days of the First Smile Campaign in the hospital during the screening of the patients by two calibrated interviewers.

The interview script consisted of a questionnaire with objective and subjective questions that aimed to address the emotional and social experiences of parents or caregivers of children with CL/P and how they dealt with such experiences. The questionnaire was composed of two parts: the first one, based on sociodemographic profile and pregnancy history, consisting of 20 questions, and the second one was related to the emotional and social experiences, which consisted of 15 questions, subdivided into four sections. The interviews were conducted in approximately 20 minutes in a private and quiet room of the hospital.

\section{Data Analysis}

Data were tabulated in Microsoft Excel and then analyzed using SPSS version 22.0 (IBM Corp., Armonk, NY, USA). Descriptive statistics was used (absolute and relative frequencies).

\section{Ethical Aspects}

The study design and informed consent were approved by the Ethics Committee of School of Medicine, Federal University of Ceará (Process\# 87963418.9.0000.5054). Volunteers, who fulfilled inclusion criteria, took part in this study after signing an informed written consent.

\section{Results}

A total of 41 parents or caregivers were included in the study. The majority of the respondents were female $(87.2 \%)$. It was observed that $43.9 \%$ of the interviewees were in the age range of 30 to 39 years, with a mean age of 35.15 ( \pm 8.74) years. Regarding the educational level of parents/caregivers, 39\% not completed primary education and $19.5 \%$ completed primary school. Regarding family income, $65.9 \%$ showed a minimum income less than or equal to a Brazilian minimum wage, approximately $\$ 209$ in this appraised period (Table 1).

According to the interviewees, $80.5 \%$ of the mothers received prenatal care. However, the great majority $(90.2 \% ; \mathrm{n}=37)$ of the parents were not prenatally diagnosed to have CL/P babies. In only $9.8 \%$ of the cases, the child was born prematurely. Approximately $54 \%$ of the parents had a male affected child. Only $7.3 \%$ of the parents were close relatives. Moreover, $46.3 \%$ of the respondents reported having another family 
member with CL/P. The majority of mothers (56.1\%) did not use teratogenic substances during pregnancy; however, $12.2 \%$ consumed cigarettes and $7.3 \%$ alcohol during the gestational period (Table 2 ).

Table 1. Socioeconomic characteristics of participating parents/caregivers.

\begin{tabular}{lc}
\hline \multicolumn{1}{c}{ Variables } & $\mathbf{N}(\%)$ \\
\hline Age Distribution & $2(4.9)$ \\
Up to 19 Years & $8(19.4)$ \\
$20-29$ Years & $18(43.9)$ \\
30- 39 Years & $10(24.4)$ \\
40 or Older & $3(7.3)$ \\
Did not Respond & \\
Educational Level & $1(2.4)$ \\
$\quad$ Illiterate & $16(39.0)$ \\
Not Completed Primary Education & $8(19.5)$ \\
Completed Primary Education & $3(7.3)$ \\
Not Completed High School & $7(17.1)$ \\
Completed High School & $1(2.4)$ \\
Completed Undergraduate Education & $5(12.2)$ \\
Not Sure & \\
Family Income (Brazilian Minimum Wages) & $15(36.6)$ \\
$<1$ & $12(29.3)$ \\
1 & $4(9.8)$ \\
1,5 & $3(7.3)$ \\
$\geq 2$ & $7(17.1)$ \\
\hline
\end{tabular}

Table 2. Distribution of respondents according to pregnancy history.

\begin{tabular}{lc}
\hline \multicolumn{1}{c}{ Variables } & $\mathbf{N}(\%)$ \\
\hline Prenatal Care & $33(80.5)$ \\
Yes & $2(4.9)$ \\
No & $6(14.6)$ \\
Not Sure & \\
CL/P Diagnosis & $37(90.2)$ \\
After Birth & $2(4.9)$ \\
During Prenatal & $2(4.9)$ \\
Not Sure & \\
Gestational Period & $34(82.9)$ \\
Full-term Birth (9 months) & $4(9.8)$ \\
Premature Birth & $3(7.3)$ \\
Not Sure & $3(7.3)$ \\
Parental Consanguinity & $26(63.4)$ \\
Yes & $12(29.3)$ \\
No & \\
Did not Answer & $19(46.3)$ \\
Familial Cases of Oral Clefts & $20(48.8)$ \\
Yes & $2(4.9)$ \\
No & \\
Not Sure & $5(12.2)$ \\
Use of Teratogenic Substances & $3(7.3)$ \\
Smoking & $1(2.4)$ \\
Alcohol Consumption & $1(2.4)$ \\
Drugs & $23(56.1)$ \\
Others & $8(19.5)$ \\
Did not Use any Substances &
\end{tabular}


When questioned about the diagnosis of the fissure, more than half of the respondents (56.1\%) pointed out that it was presented in a clarifying way. However, $48.8 \%$ of the total respondents mentioned that they had never received an explanation about what oral clefts are. The majority of the participants (63.4\%) stated that the first treatment option was corrective surgery of the fissure and $85.4 \%$ answered that they had an interest in seeking a dental service after cheiloplasty and/or palatoplasty (Table 3).

Table 3. Distribution according to information diagnosis, treatment and follow-up.

\begin{tabular}{lc}
\hline \multicolumn{1}{c}{ Variables } & N (\%) \\
\hline Diagnosis was Given in a Clarifying Way & $23(56.1)$ \\
Yes & $15(36.6)$ \\
No & $3(7.3)$ \\
Not Sure & $19(46.3)$ \\
Prior Guidance on Oral Clefts & $20(48.8)$ \\
Yes & $2(4.9)$ \\
No & \\
Not Sure & $26(63.4)$ \\
First Treatment Option & $2(4.9)$ \\
Corrective Surgery & $1(2.4)$ \\
Dentist & $1(2.4)$ \\
Speech Therapist & $1(2.4)$ \\
Pediatrician & $10(24.4)$ \\
Psychologist & \\
Not Sure & $35(85.4)$ \\
Dental Care Follow-up & $5(12.2)$ \\
Yes & $1(2.4)$ \\
No &
\end{tabular}

With regard to the feelings experienced by the parents or caregivers as soon after clefts' diagnosis, it was verified that 36.6\% felt "Fear", 19.5\% reported "Sadness", while 14.6\% reported "Despair/Shock" and $12.2 \%$ reported a "Normality" situation. In $29.3 \%$ of cases, the family accepted the situation with normality; however, $26.8 \%$ were worried and $9.8 \%$ reacted negatively to the situation of a member with CL/P. The child diet was the main concern (48.8\%) cited by parents/caregivers, followed by social relations (19.5\%) and $9.8 \%$ indicated that there were no difficulties or concerns about the patient with CL/P (Table 4).

Table 4. Experienced feelings, major concerns and emotional reactions of caregivers and family.

\begin{tabular}{lc}
\hline \multicolumn{1}{c}{ Variables } & N (\%) \\
\hline Feelings Experienced by Parents/Caregivers & $15(36.6)$ \\
Fear & $6(14.6)$ \\
Despair/Shock & $2(4.9)$ \\
Denial & $8(19.5)$ \\
Sadness & $1(2.4)$ \\
Resignation & $5(12.2)$ \\
Normality & $4(9.8)$ \\
Not Sure & $20(48.8)$ \\
Major Concerns with the Child & $8(19.5)$ \\
Feeding Care & $1(2.4)$ \\
Social Relations & $1(2.4)$ \\
Transport (Displacement for Treatment) & $1(2.4)$ \\
Allergic Reactions & $1(2.4)$ \\
Medical Follow-up &
\end{tabular}




\begin{tabular}{|cc}
\hline Corrective Surgery & $2(4.9)$ \\
No Difficulties & $4(9.8)$ \\
Not Sure & $3(7.3)$ \\
Family Reaction to Oral Clefts' Diagnosis & $12(29.3)$ \\
Normality & $11(26.8)$ \\
Concern & $2(4.9)$ \\
Disgust & $1(2.4)$ \\
Despair/Shock & $4(9.8)$ \\
Denial & $4(9.8)$ \\
Sadness & $1(2.4)$ \\
Resignation & $6(14.6)$ \\
Not Sure & \\
\hline
\end{tabular}

\section{Discussion}

The present study verified parents' emotional and social experiences of caring a child with CL/P. Parents or caregivers might experience a long-term child's treatment and face difficult situations in their complex journey. The feelings experienced by the participants of this study are in agreement with the literature since the main reactions reported by mothers were surprise, crying, shock, despair, denial, fear and other feelings $[6,14]$. Fear is still the main feeling that the family needs to deal with because the care and development of a child with CL/P may cause suffering and stress [14].

Most respondents indicated that feeding was the main concern. Feeding care is one of the most important difficulties that the family can face with the newborn [15]. In babies with CL/P, concerns are intensified due to abnormalities in face formation. Food intake in the first months of life may be compromised, resulting in many cases of child malnutrition [16]. Therefore, newborn feeding is largely difficult to perform in these patients. Many mothers still do not feel safe to cope with the challenges related to feeding a baby with $\mathrm{CL} / \mathrm{P}$ [17]. This issue becomes even more relevant because when added to fear and lack of experience, these concerns intensify and maybe a limiting factor for a healthy and normal infant feeding [18].

This study showed that most parents/caregivers received CL/P diagnosis after the child's birth. However, early diagnosis is important to promote family contact with specialists, favoring knowledge of different feeding techniques, avoiding weaning in possible cases and allowing the planning of neonatal and therapeutic care $[19,20]$.

Regarding the diagnosis, more than half of the interviewees stated that they were well informed about $\mathrm{CL} / \mathrm{P}$. In order to face and overcome the experiences and reactions, the family needs clarification and care, as well as continuous assistance by professionals from different areas who are prepared to listen sensitively, create a dialogue without denying the defect and highlight positive aspects [21,22]. Thus, this initial counseling should be performed with the parents to reduce parents/caregivers' expectations and promote psychological support to the family [23].

In the present study, participants showed surprise and fright, triggered by the diagnosis of CL/P at the time or after the baby's birth, as well as the lack or limited knowledge about this condition. However, the late diagnosis may justify the findings of this study, as shown previously [24]. In this way, quality care and assistance by many health professionals is an important way of a complete follow-up of these parents, providing basic care to the most advanced levels of care [25]. The psychological health of parents should also be emphasized in a coordinated multidisciplinary care [12].

It is known that children with clefts and their families may be "stigmatized" because of a perceived visible facial appearance and may have to deal with low levels of social support, experiencing discomfort, 
anxiety or rejection [26]. This psychosocial adjustment may differ in parents of children with CL/P. Regarding gender, parents of boys have a greater perception of social support than girls' parents. Besides, in cases of high household income, the self-esteem and perception of social support are greater. Therefore, it is important to note that parents from poor households may be at greater risk for psychosocial problems [14].

The majority of participants stated that the first treatment option was corrective surgery of fissure, which is in accordance with a protocol established by a specialized hospital for craniofacial anomalies with 40 years of experience [27]. Furthermore, the treatment protocol for these patients also involves a surgical approach, including alveolar bone graft surgery and orthognathic surgery [28]. According to Boztepe et al. [29], the possibility of treatment, information delivery, and support by health professionals during pregnancy or after a child's birth reduced most concerns about the effectiveness of corrective fissure surgery. In the current study, most of the respondents pointed out that they are interested in seeking dental service after corrective surgery. Guidelines for dental care should persist and parents should be advised about the importance of early dental care [30]. It should be stressed that the monitoring by a pediatric and orthodontic dentist is essential to stimulate breastfeeding, maintain good oral health and diagnose/correct malocclusions [31].

Furthermore, it must be emphasized that patients with $\mathrm{CL} / \mathrm{P}$ should receive a proper rehabilitation treatment with an interdisciplinary approach based on physiology, stability, aesthetics, hygiene conditions and the individual's expectations. Considering that children with $\mathrm{CL} / \mathrm{P}$ may face speech problems due to the presence of fistula or an unrepaired palate, palatal prosthesis may be indicated as a treatment for velopharyngeal dysfunction [32]. Ideally, all patients with CL/P should be assessed preoperatively and postoperatively to evaluate the impact of dental and surgical procedures, considering that oral clefts can modify the stomatognathic system and cause functional disorders [33].

Among the limitations of this study, the participants were selected during a multi-professional treatment campaign according to a convenience sampling. Further studies are necessary to check whether a greater sample could achieve the same results. Also, a qualitative approach/research could probably provide a more in-depth analysis of parents' emotional and social responses in relation to experiences with a CL/P child.

\section{Conclusion}

The parents and caregivers interviewed faced important emotional and social problems that must be addressed by the professional team that assists the child with CL/P. Our findings support that parents or caregivers for children with $\mathrm{CL} / \mathrm{P}$ are submitted to intense experiences and emotions that interfere significantly with their child care. Some relevant aspects were identified in this study: the emotional experiences of parents or caregivers; major difficulties and concerns about the development of the child diagnosed with CL/P. Finally, more research is necessary to explain how parents experience their child's longterm and complex treatment journey and describe parents' perspectives regarding this condition.

\section{Authors' Contributions}

\begin{tabular}{|c|c|c|}
\hline NOC & (iD) https://or & Formal Analysis and Writing - Original Draft Preparation. \\
\hline MFSM & (iD) https://orcid.org/0000-0001-7958-9265 & Investigation and Writing - Original Draft Preparation. \\
\hline $\mathrm{IFCB}$ & (iD) https://orcid.org/0000-0002-6442-8247 & Methodology and Investigation. \\
\hline MBA & (iD) https://orcid.org/0000-0003-1300-3481 & Methodology and Investigation. \\
\hline CTR & (iD) https://orcid.org/0000-0001-7756-7732 & Conceptualization, Formal Analysis, Writing - Original Draft and Writing - Review and Editing. \\
\hline BGN & (iD) https://orcid.org/0000-0002-9599-0662 & $\begin{array}{l}\text { Conceptualization, Investigation, Formal Analysis, Writing - Original Draft and Writing - } \\
\text { Review and Editing. }\end{array}$ \\
\hline
\end{tabular}

All authors declare that they contributed to critical review of intellectual content and approval of the final version to be published. 


\section{Financial Support}

None.

\section{Conflict of Interest}

The authors declare no conflicts of interest.

\section{Data Availability}

The data used to support the findings of this study can be made available upon request to the corresponding author.

\section{References}

[1] IPDTOC Working Group. Prevalence at birth of cleft lip with or without cleft palate: Data from the international perinatal database of typical oral clefts (IPDTOC). Cleft Palate Craniofac J 2011; 48(1):66-81. https://doi.org/10.1597/09-217

[2] Mbuyi-Musanzayi S, Kayembe TJ, Kashal MK, Lukusa PT, Kalenga PM, Tshilombo FK, et al. Non-syndromic cleft lip and/or cleft palate: Epidemiology and risk factors in Lubumbashi (DR Congo), a case-control study. J Craniomaxillofac Surg 2018; 46(7):1051-8. https://doi.org/10.1016/j.jcms.2018.05.006

[3] Silva HPVD, Arruda TTS, Souza KSC, Bezerra JF, Leite GCP, Brito MEF, et al. Risk factors and comorbidities in Brazilian patients with orofacial clefts. Braz Oral Res 2018; 32:e24. https://doi.org/10.1590/1807-3107bor-2018.vol32.0024

[4] Nelson P, Glenny AM, Kirk S, Caress AL. Parents' experiences of caring for a child with a cleft lip and/or palate: a review of the literature. Child Care Health Dev 2012; 38(1):6-20. https://doi.org/10.1111/j.1365-2214.2011.01244.x

[5] Lewis CW, Jacob LS, Lehmann CU. The primary care pediatrician and the care of children with cleft lip and/or cleft palate. Pediatrics 2017; 139(5):e20170628. https://doi.org/10.1542/peds.2017-0628

[6] Sreejith VP, Arun V, Cevarajan AP, Gopinath A, Sunil M. Psychological Effect of Prenatal Diagnosis of Cleft Lip and Palate: A Systematic Review. Contemp Clin Dent 2018; 9(2):304-8. https://doi.org/10.4103/ccd.ccd_673_17

[7] Steinberg JP, Gosain AK. Thirty years of prenatal cleft diagnosis: What have we learned? Plast Reconstr Surg 2015; 136(3):550-7. https://doi.org/10.1097/PRS.0000000000001533

[8] Baker SR, Owens J, Stern M, Willmot D. Coping strategies and social support in the family impact of cleft lip and palate and parents' adjustment and psychological distress. Cleft Palate Craniofac J 2009; 46(3):229-36. https://doi.org/10.1597/08-075.1

[9] Johansson B, Ringsberg KC. Parents' experiences of having a child with cleft lip and palate. J Adv Nurs 2004; 47(2):165-73. https://doi.org/10.1111/j.1365-2648.2004.03075.x

[10] Feragen KB, Semb G, Heliövaara A, Lohmander A, Johannessen EC, Boysen BM, et al. Scandcleft randomised trials of primary surgery for unilateral cleft lip and palate: 10. Parental perceptions of appearance and treatment outcomes in their 5-year-old child. J Plast Surg Hand Surg 2017; 51(1):81-7. https://doi.org/10.1080/2000656X.2016.1254642

[11] Zeytinoglu S, Davey MP. It's a privilege to smile: impact of cleft lip palate on families. Fam Syst Health 2012; 30(3):265-77. https://doi.org/10.1037/a0028961

[12] Stock NM, Costa B, White P, Rumsey N. Risk and protective factors for psychological distress in families following a diagnosis of cleft lip and/or palate. Cleft Palate Craniofac J 2020; 57(1):88-98. https://doi.org/10.1177/1055665619862457

[13] IBGE. Cidades. Available from: www.cidades.ibge.gov.br/brasil/ce/sobral/panorama]. [Accessed on July 9, 2020]. [In Portuguese].

[14] Nidey N, Moreno Uribe LM, Marazita MM, Wehby GL. Psychosocial well-being of parents of children with oral clefts. Child Care Health Dev 2016; 42(1):42-50. https://doi.org/10.1111/cch.12276

[15] Toledo Neto JL, Souza CM, Katakura EALB, Costa TV, Prezotto KH, Freitas TB. Knowledge of graduated nursing students on breast feeding newborns with cleft lip and palate. Rev Rene 2015; 16(1):21-8. https://doi.org/10.15253/2175-6783.2015000100004

[16] Nelson PA, Kirk SA, Nurs B. parents' perspectives of cleft lip and/or palate services: a qualitative interview. Cleft Palate Craniof J 2013; 50(3):275-85. https://doi.org/10.1597/1 1-293.]

[17] Lindberg N, Berglund A-L. Mothers' experiences of feeding babies born with cleft lip and palate. Scand J Caring Sci 2014; 28(1):66-73. https://doi.org/10.1111/scs.12048.]

[18] Davies K, Lin Y-L, Callery P. Parents' and children's knowledge of oral health: a qualitative study of children with cleft palate. Int J Paediatr Dent 2017; 27(4):264-72. https://doi.org/10.1111/ipd.12258

[19] Amstalden-Mendes LG, Xavier AC, Antunes DK, Ferreira AC, Tonocchi R, Fett-Conte AC, et al. Time of diagnosis of oral clefts: a multicenter study. J Pediatr 2011; 87(3):225-30. https://doi.org/10.2223/JPED.2084 
[20] Fleurke-Rozema JH, Van de Kamp K, Bakker MK, Pajkrt E, Bilardo CM, Snijders RJM. Prevalence, diagnosis and outcome of cleft lip with or without cleft palate in The Netherlands. Ultrasound Obstet Gynecol 2016; 48(4):458-63. https://doi.org/10.1002/uog.15834

[21] Tabaquim MLM, Marquesini MAM. Study of the stress of parents of patients with cleft lip and palate in a surgical process. Estud Psicol 2013; 30(4):517-24. https://doi.org/10.1590/So 103-166X2013000400005

[22] Nidey N, Moreno Uribe LM, Marazita MM, Wehby GL. Psychosocial well-being of parents of children with oral clefts. Child Care Health Dev 2016; 42(1):42-50. https://doi.org/10.1111/cch.12276

[23] Kuttenberger J, Ohmer JN, Polska E. Initial counselling for cleft lip and palate: parents' evaluation, needs and expectations. Int J Oral Maxillofac Surg 2010; 39(3):2 14-20. https://doi.org/10.1016/j.ijom.2009.12.013

[24] Maarse W, Boonacker CW, Breugem CC, Kon M, Manten GT, Van der Molen AB. A practical prenatal ultrasound classification system for common oral clefts. Prenat Diagn 2015; 35(9):894-900. https://doi.org/10.1002/pd.4631

[25] Robbins JM, Damiano P, Druschel CM, Hobbs CA, Romitti PA, Austin AA, et al. Prenatal diagnosis of orofacial clefts: association with maternal satisfaction, team care, and treatment outcomes. Cleft Palate Craniofac J 2010; 47(5):476-81. https://doi.org/10.1597/08-177

[26] Searle A, Neville P, Waylen A. Psychological growth and well-being in individuals born with cleft: An application of self-determination theory. Psychol Health 2017; 32(4):459-82. https://doi.org/10.1080/08870446.2016.1275630

[27] Freitas JA, das Neves LT, de Almeida AL, Garib DG, Trindade-Suedam IK, Yaedú RY, et al. Rehabilitative treatment of cleft lip and palate: experience of the Hospital for Rehabilitation of Craniofacial Anomalies/USP (HRAC/USP)-Part 1: overall aspects. J Appl Oral Sci 2012; 20(1):9-15. https://doi.org/10.1590/S1678-77572012000100003

[28] Freitas JA, Garib DG, Trindade-Suedam IK, Carvalho RM, Oliveira TM, Lauris Rde C, et al. Rehabilitative treatment of cleft lip and palate: experience of the Hospital for Rehabilitation of Craniofacial Anomalies-USP (HRACUSP)--part 3: oral and maxillofacial surgery. J Appl Oral Sci 2012; 20(6):673-9. https://doi.org/10.1590/S1678-77572012000600014

[29] Boztepe H, Ay A, Kerimoglu Yıldız G, Çınar S. Does the visibility of a congenital anomaly affect maternal-infant attachment levels? J Spec Pediatr Nurs 2016; 21(4):200-11. https://doi.org/10.1111/jspn.12157

[30] Vettore MV, Sousa Campos AE. Malocclusion characteristics of patients with cleft lip and/or palate. Eur J Orthod 2011; 33(3):311-7. https://doi.org/10.1093/ejo/cjq078

[31] Freitas JA, Garib DG, Oliveira M, Lauris Rde C, Almeida AL, Neves LT, et al. Rehabilitative treatment of cleft lip and palate: experience of the Hospital for Rehabilitation of Craniofacial Anomalies-USP (HRAC-USP)--part 2: pediatric dentistry and orthodontics. J Appl Oral Sci 2012; 20(2):268-81. https://doi.org/10.1590/S1678-77572012000200024

[32] Freitas JA, Garib DG, Oliveira M, Lauris RC, Almeida AL, Neves LT, et al. Rehabilitative treatment of cleft lip and palate: experience of the Hospital for Rehabilitation of Craniofacial Anomalies/USP (HRAC/USP) - Part 4: oral rehabilitation. J Appl Oral Sci 2012; 20(2):268-81. https://doi.org/10.1590/1679-775720130127

[33] Freitas JA, Trindade-Suedam IK, Garib DG, Neves LT, Almeida AL, Yaedú RY, et al. Rehabilitative treatment of cleft lip and palate: experience of the Hospital for Rehabilitation of Craniofacial Anomalies/USP (HRAC/USP) - Part 5: institutional outcomes assessment and the role of the Laboratory of Physiology. J Appl Oral Sci 2013; 21(4):383-90. https://doi.org/10.1590/S1678-77572012000600014 